\title{
Development of a molecular CAPS marker for the self-incompatibility locus in Brassica napus and identification of different $S$ alleles
}

\author{
S. Möhring ${ }^{1}$, V. HorstmanN ${ }^{2}$ and E. EsCH ${ }^{3,4}$ \\ ${ }^{1}$ Max-Planck-Institut für Züchtungsforschung, Abteilung für Pflanzenzüchtung und Ertragsphysiologie, Carl-von-Linné Weg \\ 10, D-50829 Köln; ${ }^{2}$ Lehrstuhl für Pflanzenbiotechnologie, Institut für Biologie II, Universität Freiburg, Schänzlestr. 1, D-79104 \\ Freiburg; ${ }^{3}$ Abteilung Angewandte Genetik, Universität Hannover, Herrenhäuser Str. 2, D-30419 Hannover, Germany; \\ ${ }^{4}$ Corresponding author, E-mail: esch@genetik.uni-hannover.de
}

With 3 figures and 4 tables

Received March 12, 2004/Accepted November 8, 2004

Communicated by A. M. Chevre

\begin{abstract}
Using primers annealing to $S$ locus sequences the cleaved amplified polymorphic sequences (CAPS) method was applied to develop a marker and to characterize different alleles at the self-incompatibility locus in Brassica napus. A segregating $\mathrm{F}_{2}$ population from a cross of a self-incompatible (SI) and a self-compatible parent, as well as seven SI lines representing four different $S$ alleles were used. Several primers specific to the $S$ locus in B. oleracea and B. campestris, chosen from the literature, allow polymerase chain reaction (PCR) amplification of genomic DNA. However, only one primer pair amplified a single specific and reproducible PCR fragment of the expected length in B. napus. Digestion with restriction endonucleases revealed polymorphisms for two CAPS markers absolutely linked to the $S$ locus. Using the codominant marker ef $\mathrm{MboI}$ it was possible to discriminate all three $F_{2}$ genotypes. With this marker and an additional marker using another primer pair it was possible to distinguish between three of the four different $S$ alleles and five of the seven SI lines, respectively.
\end{abstract}

Key words: Brassica napus - cleaved amplified polymorphic sequence marker $-S$ alleles — self-incompatibility

Self-incompatibility (SI) is a natural mechanism in plants that prevents inbreeding and promotes outcrossing. Brassica oleracea and $B$. campestris possess this self-recognition mechanism, but their amphidiploid descendant B. napus has lost it and is instead self-compatible (Olsson 1960). Self-incompatibility is successfully used as a pollination control mechanism in $B$. oleracea hybrid breeding. Self-incompatibility can be reintroduced into B. napus by backcrossing (MacKay 1977, Goring et al. 1992) or by resynthesis of the ancestors B. oleracea and B. campestris (Hodgkin 1986, Sundberg et al. 1987, Ozminkowski and Jourdan 1993). However, occasionally SI also occurs naturally in rapeseed cultivars. Rudloff (1991), Esch (1994) and Kuçera et al. (1995) were able to select SI plants from rapeseed breeding material.

The genetic mechanism of SI has been well-studied in $B$. oleracea and B. campestris. Self-incompatibility is controlled sporophytically by a single multiallelic locus ( $S$ locus) with multiple interactions between different $S$ alleles (Bateman 1955). Self-incompatible alleles can be inherited recessively (class II $S$ alleles) or dominantly (class I $S$ alleles) to selfcompatible alleles (Chen and Nasrallah 1990, Nasrallah et al. 1991). Nasrallah et al. (1970) found a protein involved in the SI reaction, the $S$ locus glycoprotein (SLG). A cDNA coding for the $S$-specific glycoprotein of $B$. oleracea was cloned by Nasrallah et al. (1985). Stein et al. (1991) showed by molecular genetic analysis that the $S$ locus consists of at least two genes: the SLG gene and the $S$ receptor kinase (SRK) gene. SRK is a membrane-associated protein with extracellular, transmembrane and cytoplasmic kinase domains. The nucleotide sequence of the extracellular domain is very similar to the SLG gene sequence. Boyes et al. (1991) showed that these two genes are expressed in stigma papillae. The male determinant of SI was identified by Schopfer et al. (1999). They found a $S$ locus cysteine-rich (SCR) gene linked to the $S$ locus in B. oleracea and B. campestris that is highly polymorphic in sequence and is transcribed only in the anthers. Transformation experiments proved that the $S$ locus specificity of the pollen was transferred together with the SCR gene. Independently, Suzuki et al. (1999) and Takayama et al. (2000) found an equivalent gene in B. campestris, the $S$ locus protein 11 (SP11) gene. SCR/SP11 is localized in the flanking region of the SRK gene. The interaction of these $S$ locus proteins is described in many publications, recently in Kachroo et al. (2002) and Watanabe et al. (2003). In a SI reaction, the $S$ domain of the membrane-associated SRK forms a complex with the pollen-borne SCR/SP11 protein. Formation of this complex leads to activation of the kinase domain of SRK inducing a signal transduction cascade involving phosphorylation events that finally lead to the rejection of the pollen. The SLG is supposed to stabilize the SI recognition reaction.

In addition, several $S$ locus-related (SLR) genes have been described for the Brassicaceae. Two SLR genes (SLR1, SLR2) belonging to the secreted glycoprotein type active in reproductive tissues were described by Lalonde et al. (1989) and Boyes et al. (1991). As the SLR genes are not linked to the $S$ locus, these workers proposed that the SLRs have a general function in pollination.

Brace et al. (1993, 1994), Nishio et al. $(1996,1997)$ and Park et al. (2001, 2002) successfully used a polymerase chain reaction restriction fragment length polymorphism (PCRRFLP) approach to distinguish different alleles in $B$. oleracea and B. campestris at the molecular level. All the three groups amplified PCR products of genomic DNA using primers annealing to $S$ locus sequences. The resulting PCR fragments were digested with different restriction enzymes and separated by agarose gel electrophoresis to detect polymorphisms. This 
type of marker has also been described as cleaved amplified polymorphic sequences (CAPS) (Konieczny and Ausubel 1993). In this study, the CAPS method has been applied to B. napus to characterize different $S$ alleles.

\section{Materials and Methods}

Plant materials: A segregating $\mathrm{F}_{2}$ population and several SI lines were analysed to find a molecular marker for the $S$ locus in B. napus. The segregating population $(\mathrm{P} 2)$ was derived from a cross between the SI line 3875/3/3 and the self-compatible cultivar 'Lirajet'. This population was raised and characterized phenotypically by Esch (1994) and consisted of 91 plants. The SI phenotype of six $\mathrm{F}_{2}$ individuals which showed an unexpected genotype in the marker analysis was further checked in self-pollination tests of their $F_{3}$ progeny. Ten flowers of each $\mathrm{F}_{3}$ plant were self-pollinated by hand with pollen from their own mature anthers and were protected from further pollination by bagging. The stigmas were carefully removed after $24 \mathrm{~h}$ and the SI was characterized by observing the pollen tube growth by fluorescence microscopy (Kho and Baër 1968). The seed set by selfing was checked when seedpods were ripe.

In addition, seven SI lines 8-1, 11-9, 2065, Myb, 391, 224 and 236 were screened for molecular markers to identify $S$ alleles (Table 1). The SI lines - except line 2065 - were selected from rapeseed breeding material with low erucic acid and glucosinolate content (00 quality) (Esch 1994, Möhring 2001). They set very few, if any seed, when selfpollinated. The inheritance of SI was analysed in crosses with a selfcompatible rapeseed cultivar, and was recessive for all lines selected in B. napus. The rapeseed line 2065 originated from a backcross of $B$. napus with $B$. campestris and had a dominantly inherited $S$ allele. The line $8-1$ is an offspring of the line $3875 / 3 / 3$ and was used instead in the experiments for identification of different $S$ alleles with molecular markers. The seven SI lines used together contained four different $S$ alleles (a, b, c, d; Table 1), as shown by Möhring (2001) in diallelic crosses. The self-compatible cultivar 'Lisabeth' was included in the analysis as a control.
DNA extraction, PCR conditions and digestion: Genomic DNA was extracted according to the protocol of Edwards et al. (1991).

The PCR amplification was performed with $50 \mathrm{ng}$ of genomic DNA as template in a volume of $25 \mu \mathrm{l}$ using $S$ locus-specific primers known from the literature (Table 2) under the following conditions: $75 \mathrm{~mm}$ Tris $/ \mathrm{HCl}\left(\mathrm{pH}\right.$ 9), $20 \mathrm{~mm}\left(\mathrm{NH}_{4}\right)_{2} \mathrm{SO}_{4}, 200 \mu \mathrm{M}$ each dNTP, $2 \mathrm{~mm}$ $\mathrm{MgCl}_{2}, 2 \mu \mathrm{M}$ primer, $0.5 \mathrm{U}$ Taq DNA polymerase (Eurogentec, Köln, Germany). PCR samples were covered with mineral oil and amplified in a Perkin-Elmer Cetus thermo cycler (Perkin-Elmer, Überlingen, Germany): 30 cycles of $93^{\circ} \mathrm{C}$ for $1 \mathrm{~min}, 55-60^{\circ} \mathrm{C}$ for 2 min (Table 3), $72^{\circ} \mathrm{C}$ for $3 \mathrm{~min}$ and one cycle of $72^{\circ} \mathrm{C}$ for $5 \mathrm{~min}$.

For restriction analysis of the PCR fragments, $5 \mu \mathrm{l} \mathrm{PCR} \mathrm{product}$ were incubated for $2 \mathrm{~h}$ at $37^{\circ} \mathrm{C}$ in a volume of $10 \mu \mathrm{l}$ using $1 \mathrm{U}$ of a restriction endonuclease, and subsequently resolved on a $2.5 \%$ agarose gel. Restriction with several enzymes was tried to generate polymorphisms. Finally, MspI, DdeI (Gibco BRL, Karlsruhe, Germany), MboI, SalI and XhoI (MBI Fermentas, St. Leon-Rot, Germany) were used.

\section{Results}

All nine primer pairs (Table 3) allowed successful PCR amplification of genomic DNA of the parental lines 3875/3/3 and 'Lirajet' as well as their $\mathrm{F}_{1}$ progeny. Primer pairs PS3/PS2 1 and PK5/PK4 amplified several PCR fragments of different lengths. Primer pairs 'a/b' and 'a/d' usually gave rise to a single PCR fragment but low amounts of two additional fragments were sometimes amplified. The primer combinations PS5/PS15 and NM1/NM2 produced some unspecific material as well as a single PCR fragment. PK1/PK4 exclusively led to amplification of genomic DNA in the self-compatible male parental genotype. Modification of amplification conditions did not improve the specificity of the reactions.

The specific PCR fragments all coincided with the expected length reported in the literature (Table 3), except for the PCR

\begin{tabular}{llll}
\hline Self-incompatible line & \multicolumn{1}{c}{ Origin } & \multicolumn{1}{c}{$\begin{array}{c}\text { Inheritance of } \\
\text { self-incompatibility }\end{array}$} & $S$ allele \\
\hline $3875 / 3 / 3$ & Brassica napus (00 quality) & Recessive (Esch 1994) & a \\
$8-1$ & B. napus (00 quality) & Recessive (Esch 1994) & a \\
$11-9$ & B. napus (00 quality) & Recessive (Esch 1994) & b \\
2065 & B. campestris & Dominant (Möhring 2001) & c \\
Myb & B. napus (00 quality) & Recessive (Möhring 2001) & a \\
391 & B. napus (00 quality) & Recessive (Möhring 2001) & a \\
224 & B. napus (00 quality) & Recessive (Möhring 2001) & a \\
236 & B. napus (00 quality) & Recessive (Möhring 2001) & d \\
\hline
\end{tabular}

Table 1: Self-incompatible lines used, their origin (00 quality: low erucic acid and glucosinolate content), inheritance of self-incompatibility in crosses with self-compatible cultivars and different $S$ alleles [lines containing the same $S$ allele according to diallelic crosses (Möhring 2001) are indicated with the same letter]

\begin{tabular}{|c|c|c|}
\hline Primer & Origin & Sequence $\left(5^{\prime} \rightarrow 3^{\prime}\right)$ \\
\hline $\mathrm{a}$ & Brace et al. (1993), Brassica oleracea & AGAACACTTGTATCTCCCGGT \\
\hline $\mathrm{b}$ & Brace et al. (1993), B. oleracea & CAATCTGACATAAAGATCTTG \\
\hline d & Brace et al. (1993), B. oleracea & AAGGTCAGCAG(G/C)AGCCAATC \\
\hline $\mathrm{e}$ & Brace et al. (1993), B. oleracea & CAGCATCTACTCGAGATTGAC \\
\hline f & Brace et al. (1993), B. oleracea & AAA(A/C/G)CCATCTCCACTGCAGCT \\
\hline PS3 & Nishio et al. (1996), B. oleracea & ATGAAAGGGGTACAGAACAT \\
\hline PS5 & Nishio et al. (1996), B. campestris & ATGAAAGGCGTAAGAAAAACCTA \\
\hline PS15 & Nishio et al. (1996), B. oleracea & CCGTGTTTTATTTTAAGAGAAAGAGCT \\
\hline PS18 & Nishio et al. (1996), B. campestris & ATGAAAGGTGTACGAAACATCTA \\
\hline PS21 & Nishio et al. (1996), B. oleracea & CTCAAGTCCCACTGCTGCGG \\
\hline PK1 & Nishio et al. (1997), B. oleracea & CTGCTGATCATGTTCTGCCTCTGG \\
\hline PK4 & Nishio et al. (1997), B. oleracea & CAATCCCAAAATCCGAGATCT \\
\hline PK5 & Nishio et al. (1997), B. oleracea & AGACAAAAGCAAGCAAAAGCA \\
\hline NM1 & Niikura and Matsuura (1998), B. oleracea & ACAGAACACTTGTATCTCCAGG \\
\hline NM2 & Niikura and Matsuura (1998), B. oleracea & AGCCAATCTGACATAAAGATC \\
\hline
\end{tabular}

Table 2: Origin and sequences of the $S$ locus-specific primers 
Table 3: Annealing temperature and length of the polymerase chain reaction (PCR) product using the primer pairs according to the literature and in the present study

\begin{tabular}{lclc}
\hline & \multirow{2}{*}{$\begin{array}{c}\text { Annealing } \\
\text { Pemperature }\left({ }^{\circ} \mathrm{C}\right)\end{array}$} & Length of PCR product (bp) \\
\cline { 3 - 4 } Primer pair & 58 & 1150 & \multicolumn{1}{c}{ This study } \\
\hline a/b & 60 & 1150 & $1150+$ two unspecific \\
a/d & 60 & 280 & $1150+$ two unspecific \\
e/f & 55 & 1000 & 280 \\
PS3/PS21 & 55 & 1300 & Several unspecific \\
PS5/PS15 & 55 & 1300 & $1000+$ some unspecific \\
PS15/PS18 & 58 & $900-1000$ & $370+$ some unspecific \\
PK1/PK4 & 55 & $900-1000$ & 1000, only in self-compatible \\
PK5/PK4 & 58 & 1160 & Several unspecific \\
NM1/NM2 & & $1160+$ some unspecific \\
\hline
\end{tabular}

products of PS5/PS15 and PS15/PS18. PS5/PS15 amplified a fragment of $1000 \mathrm{bp}$ and PS15/PS18 a fragment of $370 \mathrm{bp}$ instead of the expected PCR products of $1300 \mathrm{bp}$.

In conclusion, only the primer combination 'e/f' showed a specific and reproducible amplification of the expected PCR fragment of $280 \mathrm{bp}$ and it was therefore chosen for further characterization.

A polymorphism between the different genotypes of the segregating population was detected after restriction of the 'e/ $\mathrm{f}$ ' PCR fragments with the enzymes MboI, DdeI, SalI or XhoI. Restriction analysis with DdeI, SalI and XhoI allowed the discrimination of SI and self-compatible plants while all the three different genotypes could be distinguished after restriction with $M b o$ I. The $\mathrm{F}_{2}$ population $\mathrm{P} 2$ was analysed using the primer combination ' $\mathrm{e} / \mathrm{f}$ ' followed by restriction with $\mathrm{Mbo \textrm {I }}$ (Fig. 1) and DdeI, respectively.

Surprisingly, six recombinants were found although $S$ locusspecific primers were used (Table 4). In order to check if these plants were misclassified in $\mathrm{F}_{2}$ or true recombinants their $\mathrm{F}_{3}$ progeny (six to 14 individuals) were analysed with regard to their SI reaction and their ef $M b o$ I marker genotype (Table 4). The $\mathrm{F}_{3}$ progeny of four plants $(5,22,28$ and 29) formerly classified as self-compatible showed SI phenotypes. In the molecular analysis the plants showed the restriction fragment pattern of the SI parent. Consequently, these four plants were

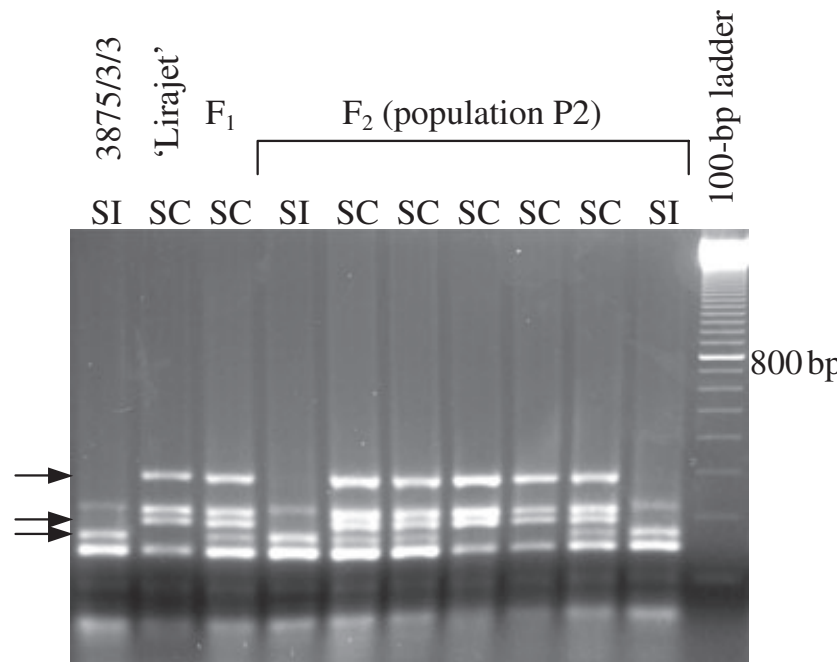

Fig. 1: $M b o$ I restricted polymerase chain reaction (PCR) fragments obtained from individuals of the $\mathrm{F}_{2}$ population $\mathrm{P} 2$, their parents $(3875$ $3 / 3$ and 'Lirajet') and the $\mathrm{F}_{1}$ genotype using the primer pair 'e/f'. SI and SC indicate a self-incompatible and self-compatible phenotype, respectively. Fragments which differentiate between the three different marker genotypes are marked by arrows
Table 4: Segregation at the self-incompatibility locus (SI: self-incompatible; SC: self-compatible, analysed by fluorescence microscopy) and the marker locus ef $\mathrm{MboI}$ (hom SI: banding pattern of the SI parent; het: banding pattern of the $\mathrm{F}_{1}$; hom $\mathrm{SC}$ : banding pattern of the $\mathrm{SC}$ parent, see Fig. 1)

\begin{tabular}{|c|c|c|c|c|c|c|c|}
\hline \multirow[b]{3}{*}{ Progeny } & \multirow[b]{3}{*}{$\mathrm{n}$} & \multicolumn{6}{|c|}{ Segregation } \\
\hline & & \multicolumn{3}{|c|}{ SI } & \multicolumn{3}{|c|}{$\mathrm{SC}$} \\
\hline & & hom SI & het & hom SC & hom SI & het & hom SC \\
\hline $\mathrm{F}_{2}$ before & 91 & 19 & $2^{\mathrm{a}}$ & - & $4^{b}$ & 42 & 24 \\
\hline $\mathrm{F}_{3} / 4^{\mathrm{a}}$ & 4 & 1 & - & - & - & 1 & 2 \\
\hline $\mathrm{F}_{3} / 77^{\mathrm{a}}$ & 6 & 3 & - & - & - & 1 & 2 \\
\hline $\mathrm{F}_{3} / 5^{\mathrm{b}}$ & 9 & 9 & - & - & - & - & - \\
\hline $\mathrm{F}_{3} / 22^{\mathrm{b}}$ & 6 & 6 & - & - & - & - & - \\
\hline $\mathrm{F}_{3} / 28^{\mathrm{b}}$ & 10 & 10 & - & - & - & - & - \\
\hline $\mathrm{F}_{3} / 29^{\mathrm{b}}$ & 14 & 14 & - & - & - & - & - \\
\hline $\mathrm{F}_{2}$ corrected & 91 & 23 & - & - & - & 44 & 24 \\
\hline
\end{tabular}

Shown are the results of the initial evaluation $\left(F_{2}\right.$ before) of the $F_{2}$ progeny. Six $F_{2}$ plants (indicated by 'a' and 'b') seemed to be recombinants. The analysis of $F_{3}$ progeny from these plants showed that they were initially misclassified (see Result for explanation). Therefore, the results of the $\mathrm{F}_{2}$ progeny were corrected $\left(\mathrm{F}_{2}\right.$ corrected). $\mathrm{n}$, total number of plants.

misclassified in $\mathrm{F}_{2}$ and their $\mathrm{F}_{2}$ phenotype was corrected to SI. Segregation was observed in the $\mathrm{F}_{3}$ progeny of the two other putative recombinants (4 and 77) classified as $\mathrm{SI}$ in $\mathrm{F}_{2}$. The molecular marker analysis confirmed the occurrence of SI and self-compatible phenotypes. Due to the results in $F_{3}$, the corresponding $\mathrm{F}_{2}$ plants must have been heterozygous at the $S$ locus and their $\mathrm{F}_{2}$ phenotype was corrected to selfcompatible. In the $F_{2}$ population with corrected phenotypes no recombinants occurred between the SI locus and the marker ef $M b o I$ (Table 4). Both CAPS markers ef $M b o I$ and ef $D d e I$ are absolutely linked to the $S$ locus. The codominant marker ef $M b o \mathrm{I}$ can distinguish between all the three different genotype classes in contrast to the dominant/recessive marker ef $D d e I$.

A 280 bp PCR fragment could also be amplified in the seven SI lines 8-1, 11-9, Myb, 391, 224, 236 and 2065 using the primer pair ' $\mathrm{e} / \mathrm{f}$ '. The PCR products were digested with the enzyme $M b o \mathrm{I}$ resulting in different restriction fragment patterns (Fig. 2). The lines 8-1, Myb, 391, 224 and 236 produced three fragments of the same size but in different amounts in several reproducible analyses. While the patterns of 8-1, 391 and 224 were very similar, the lines Myb and 236 contained more of the largest fragment. The SI line 11-9 showed a single fragment after digestion. The line 2065 demonstrated the same restriction fragment pattern as the self-compatible cultivars 'Lisabeth' and 'Lirajet' (Figs 1 and 2). 


\section{8-1 11-9 Myb 3912065224236 Lisa.}

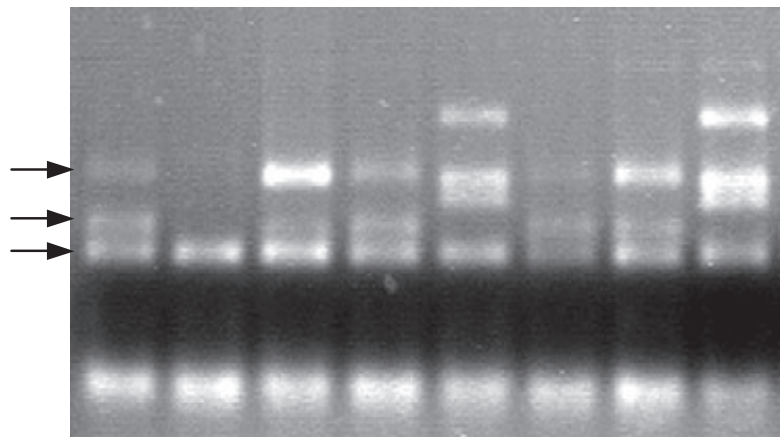

Fig. 2: $M b o \mathrm{I}$ restricted polymerase chain reaction (PCR) fragments obtained from seven self-incompatible lines and the self-compatible cultivar 'Lisabeth' (Lisa.) using the primer pair 'e/f'. The cultivar 'Lisabeth' has the same banding pattern as 'Lirajet', and 8-1 as 3875/3 3 in Fig. 1, respectively. Fragments which are discussed in the text are marked by arrows

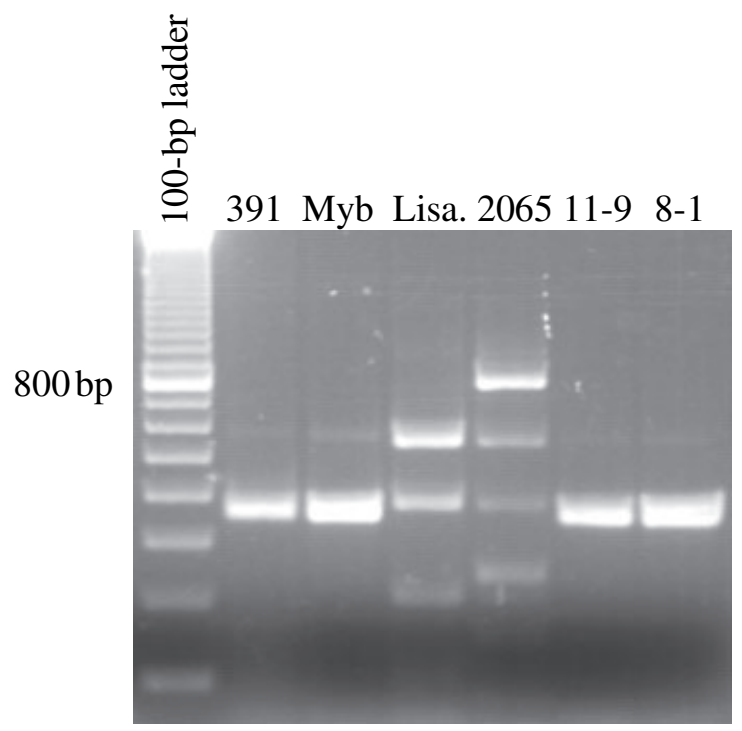

Fig. 3: $M s p$ I restricted polymerase chain reaction (PCR) fragments obtained from five self-incompatible lines and the self-compatible cultivar 'Lisabeth' (Lisa.) using the primer pair PS5/PS15

In contrast to the results with the segregating population, a $1350 \mathrm{bp}$ PCR fragment was amplified in the analysis of the different SI lines using the primer pair PS5/PS15. After restriction with the enzyme $M s p I$ the line 2065 showed a different restriction fragment pattern in comparison with the self-compatible cultivar. The SI lines 8-1, 11-9, Myb and 391 revealed a single band of $370 \mathrm{bp}$ after restriction (Fig. 3).

The marker genotypes of the lines 8-1, 11-9, Myb, 391 and 2065 shown in Figs 2 and 3 were confirmed by analysis of 10 plants per line. Two or three different plants of the lines 224 and 236 (Fig. 2) were analysed confirming the restriction fragment pattern.

\section{Discussion}

These studies show that it is possible to amplify genomic DNA in $B$. napus using $S$ locus-specific primers generated from the progenitor species of rapeseed, B. oleracea and B. campestris.
Brace et al. (1993) deduced primers from public sequences of SLG, SLR1 and SLR2 genes. Primers ' $a$ ' and ' $b$ ' were derived from highly conserved regions of the SLG, SLR1 and SLR2 genes. Primer 'd' was developed from a conserved SLG region but showed mismatching with SLR1 sequences. Brace et al. (1993) were able to amplify a single PCR fragment in B. oleracea using the primer pairs ' $a / b$ ' and ' $a / d$ '. Those results could be confirmed in the present study with B. napus using the primer combinations ' $a / b$ ' and ' $a / d$ ', but in some reactions two additional fragments were amplified. This could be due to the affinity of the primers ' $a$ ', 'b' and 'd' to SLG as well as to SLR sequences. The primers 'e' and ' $\mathrm{f}$ ' showed homology to different regions of SLG and SLR genes (Brace et al. 1993). These primers showed high specificity and amplified only one PCR fragment in all the different SI lines in the present investigation. Further analysis revealed that the restriction fragments of each sample comprised more than $280 \mathrm{bp}$. This leads to the conclusion that the $280 \mathrm{bp}$ PCR fragment derived from multiple loci showing variation in restriction sites, may result from the amphidiploid nature of $B$. napus. Cloning and sequencing of the PCR fragments could allow the assignment to the corresponding SLG and/or SLR genes.

Primers PS5 and PS18 were developed from B. campestris sequences and PS15 from B. oleracea sequences. Nishio et al. (1996) described them as class I SLG-specific primers (PS5 derived from $\mathrm{SLG}_{8}$, PS18 from $\mathrm{SLG}_{9}$ and PS15 from $\mathrm{SLG}_{6}$ ). These primers lead to the amplification of class II-specific $S$ locus sequences as well, as was confirmed in the present studies. The PCR fragments amplified in the present analyses differed from the expected lengths. The fragments in the restriction analysis of the lines 'Lisabeth' and 2065 comprised in length more than the PCR product, resulting again in the conclusion that several loci are involved.

The primer sequences of PS3 and PS21 are homologous to a class II $\mathrm{SLG}_{2 \mathrm{a}}$ sequence in B. oleracea. These primers gave a very unspecific reaction in the study. Nishio et al. (1997) could amplify class I $S$-specific sequences with the SRK-specific primers PK1, PK4 (derived from $\mathrm{SRK}_{6}$ ) and PK5 (derived from $\mathrm{SRK}_{2}$ ) but not class II $S$-specific sequences. Also in the present examination the primer combination PK1/PK4 amplified exclusively class I $S$-specific sequences present in the line 2065 and sequences of the self-compatible plants. The primers NM1 and NM2 were deduced from highly conserved regions of $\mathrm{SLG}_{6}, \mathrm{SLG}_{13}$ and $\mathrm{SLG}_{14}$ in B. oleracea and were successfully used in the differentiation of $S$ alleles in Raphanus sativus (Niikura and Matsuura 1998). In the work outlined here, these primers also amplified genomic DNA from B. napus.

All these results lead to the conclusion that highly conserved $S$ locus sequences are widespread among the Brassicaceae. Almost all primers used in this study were developed from B. oleracea sequences, and only PS5 and PS18 were deduced from B. campestris. Amplification of $S$ locus sequences in SI $B$. napus selected from breeding material and the self-compatible cultivars 'Lirajet' and 'Lisabeth' was successful with all 15 different primers described here. It is not known if these rapeseed plants carry $S$ locus sequences from one or both of their ancestors. It is not unlikely that primers derived from the conserved $S$ locus regions of the Brassicaceae amplify genomic DNA in Brassica species in general. Dwyer et al. (1991) and Kusaba et al. (1997) found higher sequence identities between $S$ alleles from the different species B. oleracea and B. campestris than within each species. Charlesworth and Awadalla (1998) suggested that the $S$ locus polymorphism existed already 
before the Brassica species diverged. Therefore, the SI system can be considered as a very ancient phylogenetic mechanism. New $S$ alleles have a strong selection advantage and exist for a long time in a population (Wright 1939).

The development of two CAPS markers absolutely linked to the $S$ locus in B. napus was demonstrated for the first time in this investigation. The $\mathrm{F}_{2}$ population $\mathrm{P} 2$ was exactly characterized by testing the $F_{3}$ progeny of $F_{2}$ plants with doubtful phenotypes. The phenotypic segregation of one SI to three selfcompatible $\mathrm{F}_{2}$ plants corresponds to the genetic segregation of one SI to two heterozygous to one self-compatible plant (Table 4). These segregation results prove that the SI in this particular plant material is controlled by just one $S$ locus but it is not known from which ancestor it was derived. Thus, with the codominant CAPS marker ef $M b o$ I one has a very useful genotyping tool for the $S$ locus in rapeseed.

Esch (1994) hybridized a cDNA probe derived from the SLG gene of the dominantly inherited $S_{29}$ allele with genomic DNA. She found two closely linked markers to the B. napus $S$ locus: an RFLP marker and an random amplified polymorphic DNA (RAPD) marker. The SLG29 probe and the clone of a gene closely linked to the $S$ locus (pW150) were used by Ekuere et al. (2004) in an RFLP analysis to determine the $S$ allele genotype in B. olerace $a$ and $B$. rapa lines, resynthesized $B$. napus lines and crosses among the resynthesized lines and rapeseed cultivars. Camargo et al. (1997) described an RFLP marker absolutely linked to the $S$ locus in their linkage map of cabbage using RFLP and RAPD markers. An RAPD marker linked with $20.2 \mathrm{cM}$ to the $S$ locus in $B$. campestris was detected by Nokazaki et al. (1997).

The seven SI lines 8-1, 11-9, Myb, 391, 224, 236 and 2065 carried four different $S$ alleles according to diallelic crosses. Three of these alleles were recessively inherited and occurred naturally in $B$. napus, whereas the dominantly inherited $S$ allele in the line 2065 was introduced from B. campestris. The analysis of the line 2065 and the self-compatible cultivar 'Lisabeth' with the marker ef $M b o$ I showed the same restriction fragment pattern. However, an analysis using the marker PS5PS15MspI succeeded in clearly distinguishing the line 2065 from the rapeseed cultivar 'Lisabeth'. All the other SI lines showed a single fragment after examination with the marker PS5PS15MspI, but differences were found between the recessively inherited SI lines using the marker ef $M b o$ I. Line 11-9 showed a single fragment after the restriction analysis and could be clearly distinguished from the other SI lines, confirming the fact that it carried a $S$ allele different from the other alleles. Lines 8-1, 391 and 224 carried the same allele according to diallelic crosses. This was confirmed in the present marker study by the identical restriction fragment pattern of these lines. Line Myb carried the same $S$ allele as 8-1, 391 and 224 and showed a similar number of fragments although differing in relative band intensity. Line 236 had the same marker genotype as line Myb but possessed a different $S$ allele according to the diallelic crosses. Further studies at the molecular level may elucidate the $S$ locus in these two lines.

It was possible to discriminate between three of the four different $S$ alleles and five of the seven SI lines, respectively, in the present investigation. Brace et al. (1994) were able to differentiate 48 SI $B$. olerace lines using the primer pair ' $a / b$ ' in combination with five different restriction enzymes with respect to different $S$ alleles. Nishio et al. (1997) distinguished 30 of $42 S$ haplotypes in $B$. oleracea using two SRK-specific primer pairs combined with four restriction enzymes. It could be very useful to characteriae as many $S$ alleles as possible with SLG- and SRK-specific primers to provide a $S$ locus typing tool in Brassica species for scientists and breeders. Such a $S$ locus typing tool facilitates the verification of crossing experiments of SI Brassica lines as well as the determination of hybridity levels in hybrid breeding.

\section{Acknowledgements}

The authors thank Prof. Dr. Günter Wricke for valuable discussion, encouragement and suggestions. This research was supported by Deutsche Saatveredelung Lippstadt-Bremen GmbH, Lippstadt, Germany.

\section{References}

Bateman, A. J., 1955: Self-incompatibility systems in angiosperms: III. Cruciferae. Heredity 9, 52-68.

Boyes, D. C., C. H. Chen, T. Tantikanjana, J. J. Esch, and J. B. Nasrallah, 1991: Isolation of a second S-locus-related cDNA from Brassica oleracea: genetic relationships between the $\mathrm{S}$ locus and two related loci. Genetics 127, 221-228.

Brace, J., D. J. Ockendon, and G. J. King, 1993: Development of a method for the identification of S alleles in Brassica oleracea based on digestion of PCR-amplified DNA with restriction endonucleases. Sex. Plant Reprod. 6, 133-138.

Brace, J., G. J. King, and D. J. Ockendon, 1994: A molecular approach to the identification of S alleles in Brassica oleracea. Sex. Plant Reprod. 7, 203-208.

Camargo, L. E. A., L. Savides, G. Jung, J. Nienhuis, and T. C. Osborn, 1997: Location of the self-incompatibility locus in an RFLP and RAPD map of Brassica oleracea. J. Hered. 88, 57-60.

Charlesworth, D., and P. Awadalla, 1998: Flowering plant selfincompatibility: the molecular population genetics of Brassica S-loci. Heredity 81, $1-9$.

Chen, C. H., and J. B. Nasrallah, 1990: A new class of S sequences defined by a pollen recessive self-incompatibility allele of Brassica oleracea. Mol. Gen. Genet. 222, 241-248.

Dwyer, K. G., M. A. Balent, J. B. Nasrallah, and M. E. Nasrallah, 1991: DNA sequences of self-incompatibility genes from Brassica campestris and Brassica oleracea: polymorphism predating speciation. Plant Mol. Biol. 16, 481-486.

Edwards, K., C. Johnstone, and C. Thompson, 1991: A simple and rapid method for the preparation of plant genomic DNA for PCR analysis. Nucleic Acids Res. 19, 1349.

Ekuere, U. U., I. A. P. Parkin, C. Bowmann, D. Marshall, and D. J. Lydiate, 2004: Latent S alleles are widespread in cultivated selfcompatible Brassica napus. Genome 42, 257-265.

Esch, E., 1994: Untersuchungen zur Selbstinkompatibilität bei Brassica napus L. im Hinblick auf die Züchtung von Hybridsorten. Dissertation. Universität Hannover, Germany.

Goring, D. R., P. Banks, W. D. Beversdorf, and S. J. Rothstein, 1992: Use of polymerase chain reaction to isolate an S-locus glycoprotein cDNA introgressed from Brassica campestris into B. napus ssp. oleifera. Mol. Gen. Genet. 234, 185-192.

Hodgkin, T., 1986: Self-incompatibility reactions in a synthetic Brassica napus line. Eucarpia Cruciferae Newsl. 11, 77-78.

Kachroo, A., M. E. Nasrallah, and J. B. Nasrallah, 2002: Selfincompatibility in the Brassicaceae: receptor-ligand signalling and cell-to-cell communication. Plant Cell (Suppl.), 227-238.

Kho, Y. O., and J. Baër, 1968: Observing pollen tubes by means of fluorescence. Euphytica 17, 298-302.

Konieczny, A., and F. Ausubel, 1993: A procedure for mapping Arabidopsis mutations using codominant ecotype specific PCR based markers. Plant J. 4, 403-410.

Kuçera, V., M. Vyvadilová, and D. Tomášková, 1995: Development of Self-incompatible Lines of Winter Rape by means of Doubled 
Haploid System. Proc. 9th Int. Rapeseed Cong., Cambridge, 89-91.

Kusaba, M., T. Nishio, Y. Satta, K. Hinata, and D. Ockendon, 1997 : Striking sequence similarity in inter- and intra-specific comparisons of class I SLG alleles from Brassica oleracea and Brassica campestris: implications for the evolution and recognition mechanism. Proc. Natl Acad. Sci. U S A 94, 7673-7678.

Lalonde, B. A., M. E. Nasrallah, K. G. Dwyer, C. H. Chen, B. Barlow, and J. B. Nasrallah, 1989: A highly conserved Brassica gene with homology to the $\mathrm{S}$ locus specific glycoprotein structural gene. Plant Cell 1, 249-258.

MacKay, G. R., 1977: The introgression of S alleles into forage rape, Brassica napus L. from turnip, Brassica campestris L. ssp. rapifera. Euphytica 26, 511-519.

Möhring, S., 2001: Selektion und Vermehrung selbstinkompatibler Winterrapslinien (Brassica napus L.) im Hinblick auf die Entwicklung von Hybridsorten. Dissertation, Universität Hannover, Germany.

Nasrallah, M. E., J. T. Barber, and D. H. Wallace, 1970: Selfincompatibility proteins in plants: detection, genetics and possible mode of action. Heredity 25, 23-27.

Nasrallah, J. B., T. H. Kao, M. L. Goldberg, and M. E. Nasrallah, 1985: A cDNA clone encoding an S locus specific glycoprotein from Brassica oleracea. Nature 318, 263-267.

Nasrallah, J. B., T. Nishio, and M. E. Nasrallah, 1991: The selfincompatibility genes of Brassica: expression and the use in genetic ablation of floral tissues. Annu. Rev. Plant Physiol. Plant Mol. Biol. 42, 393-422.

Niikura, S., and S. Matsuura, 1998: Identification of self-incompatibility alleles (S) by PCR-RFLP in radish (Raphanus sativus L.). Euphytica 102, 379-384.

Nishio, T., M. Kusaba, M. Watanabe, and K. Hinata, 1996: Registration of $\mathrm{S}$ alleles in Brassica campestris L. by the restriction fragment sizes of SLGs. Theor. Appl. Genet. 92, 388-394.

Nishio, T., M. Kusaba, K. Sakamoto, and D. J. Ockendon, 1997: Polymorphism of the kinase domain of the $\mathrm{S}$ locus receptor kinase gene (SRK) in Brassica oleracea L. Theor. Appl. Genet. 95, $335-342$.

Nokazaki, T., A. Kumazaki, T. Koba, K. Ishikawa, and H. Ikehashi, 1997: Linkage analysis among loci for RAPDs, isoenzymes and some agronomic traits in Brassica campestris. Euphytica 95, $115-123$.
Olsson, G., 1960: Self-incompatibility and outcrossing in rape and white mustard. Hereditas 46, 241-252.

Ozminkowski, R. H. Jr, and P. S. Jourdan, 1993: Expression of selfincompatibility and fertility of Brassica napus L. resynthesized by interspecific somatic hybridization. Euphytica 65, 153-160.

Park, J. I., I. S. Nou, S. S. Lee, K. K. Kang, and M. Watanabe, 2001: Identification of S-genotypes by PCR-RFLP in breeding lines of Brassica. Mol. Cells 12, 227-232.

Park, J. I., S. S. Lee, M. Watanabe, Y. Takahata, and I. S. Nou, 2002: Identification of S-alleles using polymerase chain reaction-cleaved amplified polymorphic sequence of the S-locus receptor kinase in inbreeding lines of Brassica oleracea. Plant Breeding 121, 192-197. Rudloff, E., 1991: Results and Problems in Building up Self-incompatible Lines and their use in Hybrid Seed Production of Winter Rape (Brassica napus L.). Proc. 8th Int. Rapeseed Cong., Saskatoon, $107-112$.

Schopfer, C. R., M. Nasrallah, and J. B. Nasrallah, 1999: The male determinant of self-incompatibility in Brassica. Science 286, $1697-1700$.

Stein, J. C., B. Howlett, D. C. Boyes, M. E. Nasrallah, and J. B. Nasrallah, 1991: Molecular cloning of a putative receptor protein kinase gene encoded at the self-incompatibility locus of Brassica oleracea. Proc. Natl Acad. Sci. U S A 88, 8816-8820.

Sundberg, E., M. Landgren, and K. Glimelius, 1987: Fertility and chromosome stability in Brassica napus resynthesized by protoplast fusion. Theor. Appl. Genet. 75, 96-104.

Suzuki, G., N. Kai, T. Hirose, K. Fukui, T. Nishio, T. Takayama, A. Isogai, M. Watanabe, and K. Hinata, 1999: Genomic organization of the S locus: identification and characterization of genes in $S L G$ / $S R K$ region of an $\mathrm{S}^{9}$ haplotype of Brassica campestris (syn. rapa). Genetics 152, 391-400.

Takayama, S., H. Shiba, M. Iwano, H. Shimosato, F.-S. Che, N. Kai, M. Watanabe, G. Suzuki, K. Hinata, and A. Isogai, 2000: The pollen determinant of self-incompatibility in Brassica campestris. Proc. Natl Acad. Sci. U S A 97, 1920-1925.

Watanabe, M., S. Takayama, A. Isogai, and K. Hinata, 2003: Recent progresses on self-incompatibility research in Brassica species. Breeding Sci. 53, 199-208.

Wright, S., 1939: The distribution of self-sterility alleles in populations. Genetics 24, 538-552. 